COMMENT. Cognitive development of children exposed in utero to LEV is not delayed under age 24 months. Testing of cognitive outcome in school-age children is indicated to exclude longer-term effects of in utero exposure to LEV. Childhood exposure (ages 4-16 years) to LEV as adjunctive therapy for partial seizures in 46 patients vs 27 taking placebo found no significant differences in neurocognitive effects. LEV was effective and well tolerated. (Levisohn PM, Mintz M, Hunter SJ et al. LEV Study Group. Epilepsia 2009;50(11):2377-2389). LEV is indicated as adjunctive therapy for partial seizures (Browne TR, Holmes GL, 2004) and is also effective in children with generalized seizures (Lee YJ et al. Pediatr Neurol 2010;42(2):86-92). Drowsiness, dizziness, behavioral problems, and irritability are reported side effects, but they rarely require drug withdrawal.

Efficacy and tolerability of levetiracetam in children with epilepsy. (Li J, Xiao N, Chen S. Brain Dev Feb 2011;33:154-151). In a prospective trial of levetiracetam in 120 children (mean age $4.5+/-3.9$ years) with partial (44\%) and generalized (29\%) seizures, $65 \%$ were seizure free, and $83 \%$ had a seizure reduction of $>50 \%$. Patients with infantile spasms $(n=15)$ had complete seizure control in $40 \%$. Average duration of follow-up was $10.3+/-3.5$ months. Side effects included somnolence, nervousness, and dysphoria in $47 \%$, and $4 \%$ discontinued treatment because of side effects. One-year retention rate of levetiracetam was $73 \%$, similar to that in a previous large study cohort (Despondt C et al. J Neurol Neurosurg Psychiatry 2006;77:10-13).

\title{
VERBAL VS NON-VERBAL COGNITIVE OUTCOMES AT 3 YEARS AFTER FETAL AED EXPOSURE
}

Verbal and non-verbal cognitive abilities were assessed at 3 years of age in 216 children exposed in utero to commonly used antiepileptic drugs. The investigation was an ongoing prospective multicenter study in the USA and UK, involving pregnant females with epilepsy on monotherapy with carbamazepine, lamotrigine, phenytoin or valproate, from 1999 to 2004. Tests included Differential Ability Scales, Preschool Language Scale, Peabody Picture Vocabulary Test and Developmental Test of Visual-Motor Integration. Verbal scores were lower than non-verbal in children exposed to each drug. They were higher if mother received preconceptional folate. Valproate was associated with poorer cognitive outcomes, both verbal and non-verbal, and the negative effect was dose related. Carbamazepine had a negative, dose related effect on verbal performance. Effects of lamotrigine and phenytoin on cognitive performance were not dose related. Fetal AED exposure may alter language development and normal cerebral lateralization. Preconceptional folate may improve cognitive outcomes. (Meador KJ, Baker GA, Browning N, et al. Foetal antiepileptic drug exposure and verbal versus non-verbal abilities at three years of age. Brain Feb 2011;134:396-404). (Respond: Kimford J Meador MD, Department of Neurology, Emory University, 101 Woodruff Circle, Suite 6000, Atlanta, GA 30322. E-mail: kimford.meador@emory.edu).

COMMENT. This study provides further evidence of the adverse cognitive outcome in young children exposed to some common AEDs in utero, and the negative dose related effects on both verbal and non-verbal performance associated with fetal 
valproate exposure. These findings are in contrast to the absence of delayed cognitive performance in children exposed in utero to levetiracetam.

\section{PREVALENCE OF VIGABATRIN-INDUCED VISUAL FIELD LOSS}

The magnitude of risk of vigabatrin-associated visual field loss and any clinical predictors of risk were determined by systematic review of 32 studies identified by electronic searches of the literature. Reports were analyzed at the Universities of Liverpool, Cardiff, Birmingham, and Warwick, Coventry, UK. Of 1,678 patients exposed to vigabatrin, $738(44 \%)$ had visual field loss compared to $30(7 \%)$ among 406 controls. The random-effects estimate for the proportion of children with visual field loss was $34 \%$ compared to $52 \%$ for adults. The relative risk for visual field loss was 4.0 . Risk factors for a higher proportion of patients with visual field loss were a larger mean cumulative dose of vigabatrin and increasing age. The authors conclude that vigabatrin should be reserved for patients with epilepsies known to be unresponsive to other alternative therapies or for patients receiving benefit from vigabatrin that outweighs the risk. (Maguire MJ, Hemming K, Wild JM, Hutton JL, Marson AG. Prevalence of visual field loss following exposure to vigabatrin therapy: A systematic review. Epilepsia Dec 2010;51(12):2423-2431). (Respond: Dr Melissa Maguire, Newcastle General Hospital, Westgate Rd, Newcastle-upon-Tyne, NE4 6BE, UK. E-mail: maguirem@doctors.org.uk).

COMMENT. Vigabatrin, an analog of GABA, irreversibly inhibits GABA transaminase, and increases brain levels of GABA. Bilateral concentric constriction of visual fields with relative sparing of the temporal fields, first reported in 1997, affects one third of children and one half of adults treated with vigabatrin. Apart from age, male gender, and cumulative dose over time, risk factors for this adverse effect of vigabatrin are unknown. Its use in children is restricted to patients with infantile spasms and tuberous sclerosis and as adjuvant therapy for partial seizures refractory to alternative treatments. Visual field examination is required prior to and at intervals during treatment. The intervals and optimal frequency of perimetry has not been determined. Ongoing research concerning risk factors and early detection of visual field loss associated with vigabatrin includes a possible genetic predisposition and use of imaging as a biomarker of nasal retinal nerve fiber attenuation (Moseng L et al. Acta Ophthalmol Jan 21, 2011;10:1111). Several studies show that the visual field loss may be permanent.

\section{SEIZURE DISORDERS}

\section{REVISED AAP PRACTICE GUIDELINES FOR EVALUATION OF THE CHILD WITH A SIMPLE FEBRILE SEIZURE}

An AAP subcommittee on febrile seizures has revised the practice guidelines of 1996 for the diagnosis and evaluation of a simple febrile seizure in children 6 months through 60 months of age. Articles published since the last guideline through 2009 were reviewed, and recommendations were assessed until consensus was reached. The committee notes that the following do not indicate an exclusive course of treatment, and variations according to individual circumstances may be appropriate: 